\title{
Ketamine, at a Dose that Disrupts Motor Behavior and Latent Inhibition, Enhances Prefrontal Cortex Synaptic Efficacy and Glutamate Release in the Nucleus Accumbens
}

\author{
Florence Razoux', René Garcia' and Isabelle Léna*,' \\ 'INSERM Equipe Avenir, Laboratoire de Neurobiologie et Psychopathologie, Université de Nice-Sophia Antipolis, Parc Valrose, Nice cedex 2, \\ France
}

\begin{abstract}
Noncompetitive N-methyl-D-aspartate (NMDA) antagonists such as ketamine represent useful pharmacological tools to model, in both healthy humans and rodents, behavioral and cerebral abnormalities of schizophrenia. These compounds are thought to exert some of their disruptive effects by impairing glutamatergic transmission in corticolimbic circuits including the nucleus accumbens (NAc). In this study, we investigated in freely moving rats behavioral changes as well as electrophysiological and neurochemical alterations in the NAc following acute systemic injection of a subanesthetic dose $(25 \mathrm{mg} / \mathrm{kg})$ of ketamine. We found that ketamine induced an immediate behavioral activation, characterized by hyperlocomotion, stereotypies and ataxia, and abolished latent inhibition in a conditioned-fear paradigm when injected at the pre-exposure stage. We also observed that during expression of motor effects which are thought to be related to the positive symptoms of schizophrenia, ketamine potentiated synaptic efficacy in the prefrontal-accumbens pathway and increased the extracellular levels of glutamate in the NAc. These results, taken together with previous findings, suggest that the psychoticlike effects of noncompetitive NMDA antagonists may be, in part, mediated by an increase in glutamate release in the NAc associated with synaptic changes in accumbens glutamatergic inputs including enhancement of synaptic efficacy in the prefrontal input.

Neuropsychopharmacology (2007) 32, 719-727. doi:I 0.1038/sj.npp. I30 I057; published online 8 March 2006
\end{abstract}

Keywords: noncompetitive NMDA antagonist; schizophrenia; limbic system; synaptic plasticity; microdialysis; rats

\section{INTRODUCTION}

Pharmacological blockade of $N$-methyl-D-aspartate (NMDA) glutamate receptors has been proposed as a relevant model of schizophrenia in humans and animals. Indeed, administration of noncompetitive NMDA antagonists such as phencyclidine (PCP) or ketamine to healthy volunteers induces a schizophrenia-like syndrome including positive and negative symptoms as well as cognitive dysfunction (Luby et al, 1959; Krystal et al, 1994; Malhotra et al, 1996). Moreover, these compounds have been shown to exacerbate the symptomatology of schizophrenic patients (Luby et al, 1959; Lahti et al, 1995; Malhotra et al, 1997). In rodents, acute administration of PCP, ketamine or MK-801 produces hyperlocomotion and stereotypies as well as deficit in social interactions, which are thought to correspond to certain

*Correspondence: Dr I Léna, INSERM Equipe Avenir, Laboratoire de Neurobiologie et Psychopathologie, JE 244I, Université de NiceSophia Antipolis, Parc Valrose, 06108 Nice cedex 2, France, Tel: + 334 920768 19, Fax: + 334920761 62, E-mail: lena@unice.fr

Received 15 August 2005; revised II January 2006; accepted 6 February 2006

Online publication: 7 February 2006 at http:/www.acnp.org/citations/ Npp0207060505 I3/default.pdf aspects of the positive and negative symptoms of schizophrenia, respectively (Irifune et al, 1995; Sams-Dodd, 1996; Adams and Moghaddam, 1998). Noncompetitive NMDA antagonists have also been found to impair performance of several cognitive tasks in rats (Butelman, 1990; Kesner and Dakis, 1993; Verma and Moghaddam, 1996) including latent inhibition, which is disrupted in patients with acute schizophrenia (Moser et al, 2000).

On the basis of the clinical findings, it has been hypothesized that dysfunction of glutamatergic transmission, rather than dopaminergic (DA) as initially thought, might underlie the expression of schizophrenic symptoms (Javitt and Zukin, 1991; Olney and Farber, 1995). The current pathophysiological models of schizophrenia postulate that this disorder would result from a neurodevelopmental disruption of cortical glutamatergic transmission leading secondary to a dysregulation of subcortical DA system (Grace, 1991, 2000; Carlsson et al, 1999; Jentsch and Roth, 1999; Coyle et al, 2003). In particular, dysfunction in afferents and efferents of the nucleus accumbens (NAc) is thought to be implicated (Grace, 2000). Indeed, the NAc, which constitutes the main part of the ventral striatum, receives glutamatergic projections from the medial prefrontal cortex (mPFC), hippocampus, and basolateral 
amygdala in addition to a massive DA innervation from the ventral tegmental area (VTA) (Sesack and Pickel, 1990; Zahm and Brog, 1992). Furthermore, postmortem and imaging studies of brains of schizophrenic patients have consistently reported structural and functional abnormalities in the PFC (Weinberger et al, 1986; Glantz and Lewis, 2000; Callicott et al, 2003) and hippocampus (Bogerts et al, 1985; Csernansky et al, 1998; Heckers et al, 1998) as well as dysregulation in the striatal DA system (Laruelle et al, 1996; Breier et al, 1997; Abi-Dargham et al, 1998).

The NAc is considered as an interface between the limbic and motor systems, translating information generated by the PFC, hippocampus, and amygdala into responses to guide subsequent motor acts (Mogenson et al, 1980). Grace (2000) has proposed that schizophrenic symptoms might be subserved by a decreased activity in glutamatergic projections from both hippocampus and PFC associated with an increased influence of inputs from amygdala. This has been partially demonstrated by recent studies using the pharmacological ketamine model of schizophrenia. Indeed, this NMDA antagonist depresses synaptic efficacy between the hippocampus and the NAc (Hunt et al, 2005), while it enhances synaptic transmission between the basolateral amygdala and the NAc (Kessal et al, 2005). Such an investigation for the projection from the PFC to the NAc would be of particular interest.

The aim of the present study was therefore to examine the effect produced by systemic injection of a subanesthetic dose of ketamine on synaptic efficacy between the PFC and the NAc in freely moving rats. We first analyzed the effects induced by this dose of ketamine on psychotic-related behaviors and cognitive function using latent inhibition. A determination of the time-course effect of ketamine on the extracellular levels of glutamate in the NAc was also performed using in vivo microdialysis.

\section{MATERIALS AND METHODS}

\section{Animals}

Male Wistar rats weighing 280-350 g (Charles River, France) were used in all experiments. Animals were housed in collective cages before surgery and in individual cages after surgery. Rats were maintained on a free feeding regimen with a $12 \mathrm{~h}$ light-dark cycle. Behavioral experiments were performed during the light phase. All animal procedures were conducted in accordance with the European Community Guidelines on the care and use of laboratory animals (86/609/EEC).

\section{Surgical Procedure}

Rats were anesthetized with sodium pentobarbital $(60 \mathrm{mg} /$ $\mathrm{kg}$, i.p.) and placed in a stereotaxic apparatus with the incisor bar set at $-3.0 \mathrm{~mm}$. The skull was exposed and holes were drilled for placement of skull screws and cannula or electrodes. Electrodes, made of two twisted silver wires (110 $\mu \mathrm{m}$ diameter), were implanted ipsilaterally according to the coordinates of the atlas of Paxinos and Watson (1986): stimulating electrodes were placed, with respect to the bregma, in the prelimbic region of PFC (anterior (A), 2.7; lateral (L), 0.5-0.9; ventral $(\mathrm{V}), 3-4.5)$ and recording electrodes in the shell region of the NAc (A, 1.6; L, 0.4-0.9; $\mathrm{V}, 6.3-7.4)$. The position of the electrodes was adjusted until a maximal amplitude of the field potential was recorded. The cannula (CMA/11 microdialysis, Stockolm, Sweden) was implanted unilaterally into the shell of the NAc (A, 1.6; $\mathrm{L}, 0.8 ; \mathrm{V},-5.8)$. The screws and electrodes or cannula were secured in place with dental cement. Following surgery, rats were allowed to recover for at least 5 days before the experiments started.

\section{Locomotor Activity, Stereotypies, and Ataxia Assessment}

Motor behavior was measured during microdialysis experiments. Saline or ketamine-induced locomotor activity (total photocell beam interruptions) were monitored using an automated infrared beam-based system (Colombus, USA) placed along a rectangular cage. Beam interruptions were totaled every $5 \mathrm{~min}$. Stereotypies and ataxia were videotaped for off-line analysis. These behaviors were evaluated for $1 \mathrm{~min}$ every $5 \mathrm{~min}$ according to the rating scale of Sams-Dodd (1996).

\section{Latent Inhibition Procedure}

Latent inhibition was assessed using a conditioned freezing response paradigm in which a tone $(67 \mathrm{~dB}, 1000 \mathrm{~Hz}, 15 \mathrm{~s})$ was used as the conditioned stimulus (CS) and a mild eyelid shock $(3.5 \mathrm{~mA}, 5 \mathrm{~Hz}, 1 \mathrm{~s})$ as the unconditioned stimulus (US). Pre-exposure to the tone prior to pairing resulted in a reduction of the conditioned freezing compared to animals not pre-exposed (PE). At least 5 days before the experiments, using the same anesthesia protocol described above, two stimulating electrodes were inserted in each corner of the right eyelid of the animal in order to apply the mild shock.

The procedure consisted of a pre-exposure stage (days $1-2$ ), a conditioning stage (day 3 ), and a test stage (day 4 ). On days 1 and 2,16 CS presentations separated by a 2-min interval were delivered to the rats of the PE group, whereas the rats of the non-PE (NP) group were placed in the experimental chamber for the same duration (38 min) without any CS presentation. On the following day, PE and NP rats were given a conditioning trial consisting of a 4-min free exploration period followed by two CS-US pairings separated by a 2-min interval. Each rat was removed $2 \mathrm{~min}$ after delivery of the second CS-US presentation and returned to its home cage. An additional control group (NP and nonconditioned (NP-NC)) was used. Rats were placed for the same period of time in the conditioning chamber but neither tone nor shock were delivered. On day 4, all rats were given a 6-min period of free exploration in the experimental chamber, after which the CS was delivered during 2 min. Freezing behavior was continuously videotaped for off-line analyses. The freezing score was calculated as a percentage of the 2-min tone presentation.

To avoid contextual interference, rats were placed on days 1-3 in a transparent Plexiglas box with a smooth floor and cleaned with $1 \%$ acetic acid whereas, on the test day, the experimental chamber was different (opaque plastic box, with a rough floor cleaned with $85 \%$ ethanol). Ketamine 
( $25 \mathrm{mg} / \mathrm{kg}$ ) or saline vehicle was injected $20 \mathrm{~min}$ prior to the pre-exposure phase.

\section{In Vivo Electrophysiological Recordings}

Rats were placed in a recording chamber $\left(35 \times 35 \times 42 \mathrm{~cm}^{3}\right)$ and electrophysiological activity was recorded through a junction field effect transistor operational amplifier connected to the headstage. Cables from the amplifier were relayed by a multichannel rotating connector, allowing free movement of the rat within the experimental chamber. Standard stimulation of PFC consisted of single pulses ( $0.1 \mathrm{~ms}$ duration) delivered every $30 \mathrm{~s}$. Evoked-field potentials recorded in the NAc were amplified, filtered (gain 1000; band-pass $0.001-1 \mathrm{kHz}$ ) and digitized using a Power 1401 interface (CED, Cambridge, UK) connected to a computer for off-line analysis. Responses were measured as a function of stimulus intensity $(100-1000 \mu \mathrm{A})$ to yield input-output curves and were recorded for at least 3 days to ensure that baseline responses were stable. On the test day, the intensity corresponding to $70 \%$ of the maximal amplitude was selected as test intensity. After a baseline period of $30 \mathrm{~min}$, ketamine $(25 \mathrm{mg} / \mathrm{kg})$ or saline was injected and evoked-field potentials were recorded for an additional $120 \mathrm{~min}$. Input-output curves were determined in a separate study before and 30, 60, and $90 \mathrm{~min}$ after injection of ketamine.

\section{In Vivo Microdialysis}

On the day of the microdialysis experiment, rats were placed in a Plexiglas cage $\left(35 \times 35 \times 38 \mathrm{~cm}^{3}\right)$ and the probe (CMA/11, $240 \mu \mathrm{m}$ diameter, $20 \mathrm{kDa}$ cutoff, $2 \mathrm{~mm}$ membrane length) was inserted into the cannula. The probe was perfused with Ringer's solution $\left(\mathrm{NaH}_{2} \mathrm{PO}_{4}, 0.45 \mathrm{mM} ; \mathrm{Na}_{2} \mathrm{HPO}_{4}\right.$, $2.33 \mathrm{mM} ; \mathrm{CaCl}_{2}, 1 \mathrm{mM}$; NaCl, $149 \mathrm{mM} ; \mathrm{KCl}, 2.8 \mathrm{mM} ; \mathrm{MgCl}_{2}$, $1 \mathrm{mM} ; \mathrm{pH}=7.4$ ) at a flow rate of $1.0 \mu \mathrm{l} / \mathrm{min}$. The probe was connected to the microperfusion pump via a dual-channel liquid swivel coupled to a balance arm (Instech, Plymouth, USA), allowing free movement of the animal during the experiment. After a 4-h stabilization period, dialysates samples were collected at 5-min intervals and stored at $-80^{\circ} \mathrm{C}$ before analyses by capillary electrophoresis. Four dialysate samples were used to determine basal levels. Then, rats were injected with ketamine $(25 \mathrm{mg} / \mathrm{kg})$ or saline and samples were collected for an additional $145 \mathrm{~min}$. To synchronize motor activation with sample collection, the time delay due to the dead volume of the microdialysis system (probe and output tubing) was taken into account.

\section{Capillary Electrophoresis Analysis of Glutamate}

The dialysate samples $(5 \mu \mathrm{l})$ were analyzed for glutamate content using an automatic P/ACETMMDQ system (Beckman-Coulter, Fullerton, USA) equipped with an external laser-induced fluorescence ZETALIF detector (Picometrics, Ramonville, France). The excitation was performed by a He-Cd laser (Liconix, Santa Clara, CA) at a wave length of $442 \mathrm{~nm}$. Separations were carried out with a fused-silica capillary $(50 \mu \mathrm{m}$ internal diameter $)$. The method used was adapted from that previously described by Bert et al (1996).
Dialysates and standard solutions were derivatized by adding a mixture containing the internal standard (aminoadipic acid (AAD)), a borate/sodium cyanide $(\mathrm{NaCN})$ solution and naphthalene-2,3-dicarboxaldehyde (NDA) as the fluorogen agent. Glutamate analysis was performed using $75 \mathrm{mM}$ borate buffer ( $\mathrm{pH} \mathrm{9.2)} \mathrm{at} \mathrm{a} \mathrm{voltage} \mathrm{of} 25 \mathrm{kV}$.

\section{Drugs and Chemicals}

NDA and $\mathrm{NaCN}$ were purchased from Fluka (Buchs, Switzerland). Ketamine hydrochloride, DL-glutamate, AAD, boric acid, and sodium tetraborate were obtained from Sigma (St Louis, MO, USA), mono and dibasic sodium phosphate from Carlo Erba (Rodano, Italia). Ketamine was dissolved in $0.9 \%$ saline solution and injected intraperitoneally (i.p.) in a volume of $1 \mathrm{ml} / \mathrm{kg}$.

\section{Histology}

After completion of microdialysis and electrophysiological experiments, rats were anesthetized and their brains rapidly removed. Serial sections of $25 \mu \mathrm{m}$ were performed on a cryostat and stained with cresyl violet for verification of electrode or probe placement.

\section{Data Analysis}

Statistical analysis of the conditioned freezing response was performed using one-way (pilot study) or two-way ANOVA (treatment $\times$ condition) followed by Newman-Keuls test for post hoc comparisons. Comparisons between stereotypies and ataxia scores in the ketamine group and the saline group were performed using the nonparametric MannWhitney test. The data from other experiments were analyzed using two-way ANOVA with time or intensity as the repeated measures and treatment as the between-group factor. Post hoc comparisons were performed using Student or Newman-Keuls test.

\section{RESULTS}

\section{Effects of Ketamine on Locomotor Activity, Stereotypies, and Ataxia}

Figure 1a represents the change as a function of time in locomotor activity of rats after intraperitoneal injection of $25 \mathrm{mg} / \mathrm{kg}$ ketamine or saline. Ketamine produced a significant increase in locomotor activity compared to the control group as revealed by a two-way ANOVA analysis with a significant treatment effect $(\mathrm{F}[1,8]=28.6$; $p=0.0011)$, time effect $(\mathrm{F}[32,256]=14.82 ; p<0.0001)$ and treatment $\times$ time interaction $(\mathrm{F}[32,256]=12.12 ; p<0.0001)$. Locomotor activity increased immediately and reached a maximal value at 10 -min postinjection. Post hoc comparisons indicated that the hyperlocomotion induced by ketamine was significant, compared to saline group, between 5 and $40 \mathrm{~min}$ after injection.

The time-course effect produced by ketamine on stereotyped behavior is shown in Figure $1 \mathrm{~b}$ and the temporal pattern obtained was similar to that observed with locomotor activity. Indeed, stereotypies induced by ketamine reached maximal scores at 10 -min postinjection and 

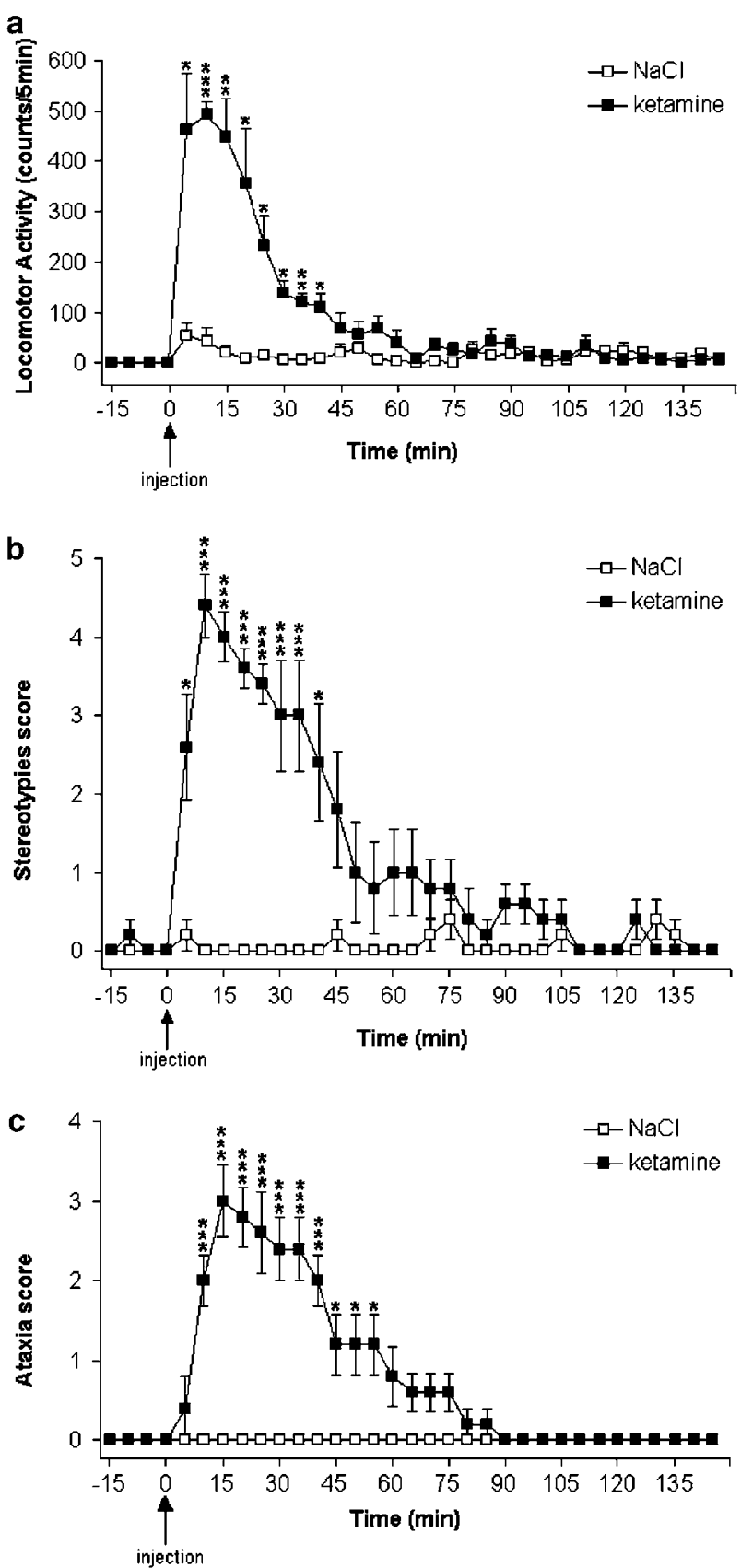

Figure I Time-course effects of ketamine or saline on (a) locomotor activity, (b) stereotypies and (c) ataxia. Each point represents the mean \pm SEM of five animals. ${ }^{*} p<0.05$, ${ }^{*} * x<0.01$, and ${ }^{* * *} p<0.00$ I indicate significant differences from the saline-treated group corresponding to the same postinjection time (Student or Mann-Whitney test).

their values were significantly different from those of control rats between 5 and $40 \mathrm{~min}$ after ketamine injection (Mann-Whitney test).

Ketamine also produced ataxia (Figure 1c), which was moderate according to the scale of Sams-Dodd (1996). Analysis of these data with nonparametric Mann-Whitney test revealed that ataxia scores in ketamine-treated rats were significantly different from those of saline-injected rats between 10 and $55 \mathrm{~min}$ following ketamine injection. Ataxia scores were maximal $15 \mathrm{~min}$ after injection.

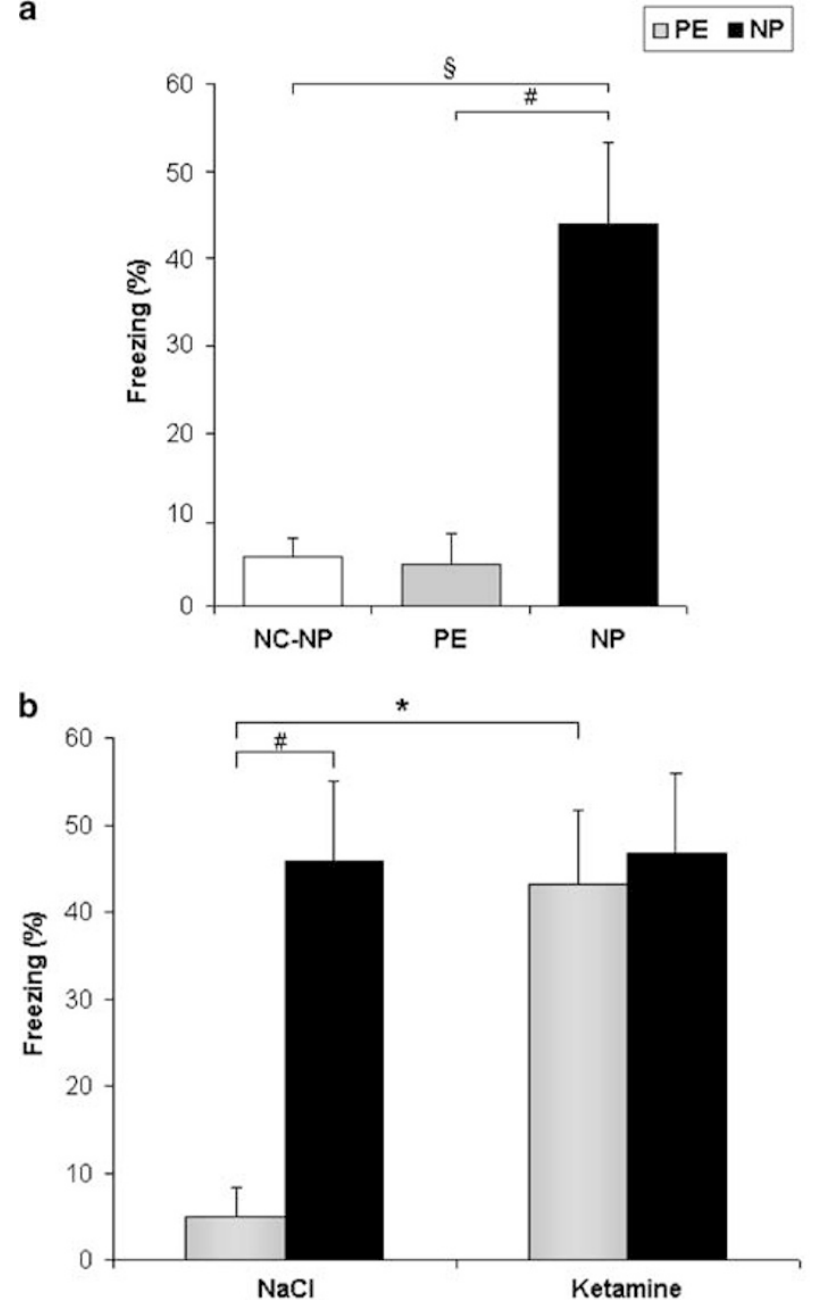

Figure 2 Latent inhibition test. (a) Effect of pre-exposure and conditioning to the conditioned stimulus (CS) on the freezing response in conditioned non-pre-exposed (NP), pre-exposed (PE) and nonconditioned NP (NC-NP) rats. (b) Effect of ketamine on latent inhibition. Values are expressed as percentage (mean \pm SEM) of freezing during the 2-min CS presentation $(n=6-8) .{ }_{p}^{{ }_{p}}<0.05$ indicates a significant conditioning effect, ${ }^{\#} p<0.05$ indicates a significant pre-exposure effect and ${ }^{*} p<0.0$ I indicates a significant treatment effect (Newman-Keuls test)

\section{Effect of Ketamine on Latent Inhibition in a Conditioned-Fear Paradigm}

The result of a pilot study performed in order to validate our protocol is represented in Figure 2a. As expected, oneway ANOVA analysis indicated that conditioned NP rats displayed a significantly higher percentage of freezing during the CS presentation than rats from NC-NP group $(p<0.05)$. The duration of freezing in the PE group was also significantly lower than that observed in the NP group $(p<0.05)$, indicating a latent inhibition effect in the PE group.

The percentage of freezing during CS presentation for $\mathrm{PE}$ and NP rats after saline or ketamine treatment is shown in Figure $2 \mathrm{~b}$. Intraperitoneal injection of $25 \mathrm{mg} / \mathrm{kg}$ ketamine before the pre-exposure stage induced a significant disruption of latent inhibition compared to the saline group as 
shown by a two-way ANOVA analysis with a significant treatment effect $(\mathrm{F}[1,25]=6.38 ; p=0.018)$, pre-exposure effect $(\mathrm{F}[1,25]=6.93 ; p=0.014)$ and treatment $\times$ pre-exposure interaction $(\mathrm{F}[1,25]=4.74 ; p<0.05)$.

\section{Effect of Ketamine on Synaptic Transmission between the Prefrontal Cortex and the NAc}

Field potentials evoked by stimulation of the prelimbic region of the PFC in the shell of the NAc were characterized by a positive component with a peak latency of 10-12 ms, consistent with a monosynaptic activation (Figure 3a). Our data are in agreement with those recently reported by Goto and Grace (2005a) in anesthetized rats. Indeed, these authors have found that in vivo PFC stimulation evoked field potentials with a positive component in the shell region of the NAc but a negative component in the core region. Schematic drawings of electrode placement after histological verification are shown in Figure 4a (stimulation) and Figure 4b (recording).

Acute systemic injection of ketamine at a subanesthetic dose of $25 \mathrm{mg} / \mathrm{kg}$ i.p. induced potentiation ( $\sim 20 \%$ from baseline) of the amplitude of the positive component of the PFC-NAc field potential (Figure 3b). Changes in the positive component were immediate and maximal between 10 and $40 \mathrm{~min}$ after ketamine injection. Then, the amplitude decreased progressively before returning to baseline values at 95-min postinjection. Injection of saline did not alter the field potential amplitude. A two-way ANOVA analysis on these data indicated a significant effect of treatment $(\mathrm{F}[1,10]=29.13 ; p=0.0003)$, of time $(\mathrm{F}[30,300]=$ $6.61 ; p<0.0001)$ and their interaction $(\mathrm{F}[30,300]=5.97$; $p<0.0001$ ).

In a separate study, the effect induced by ketamine on NAc evoked potentials was evaluated by complete inputoutput curves obtained before and 30,60, and $90 \mathrm{~min}$ after injection (Figure 3c). Two-way ANOVA with intensity as the repeated measures indicated a significant effect of treatment $(\mathrm{F}[3,24]=2.91 ; p=0.05)$ and intensity $(\mathrm{F}[9,216]=350.36$; $p<0.0001$ ) with no significant interaction between treatment and intensity. Post hoc analysis revealed that $30 \mathrm{~min}$ after ketamine injection, the amplitude of the positive component was significantly different from baseline group for intensities of stimulation $\geqslant 600 \mu \mathrm{A}$ whereas 60 min after injection, the amplitude was significantly increased compared to baseline group for intensities of stimulation $\geqslant 900 \mu \mathrm{A}$. At $90-\mathrm{min}$ postinjection, ketamine induced a significant increase in the amplitude only for an intensity of stimulation of $1000 \mu \mathrm{A}$.

\section{Effect of Ketamine on the Extracellular Levels of Glutamate in the NAc}

The mean concentrations of glutamate obtained in dialysates (not corrected for in vitro recovery) from the NAc before saline or ketamine injection were $10.1 \times 10^{-7} \mathrm{M}$ \pm 2.14 and $9.2 \times 10^{-7} \mathrm{M} \pm 2.99$, respectively.

Acute systemic injection of ketamine at a dose of $25 \mathrm{mg} / \mathrm{kg}$ i.p. induced a significant increase of $\sim 120 \%$ in the extracellular levels of glutamate in the shell region of NAc compared to the control group (Figure 5). Two-way ANOVA analysis revealed a significant treatment effect
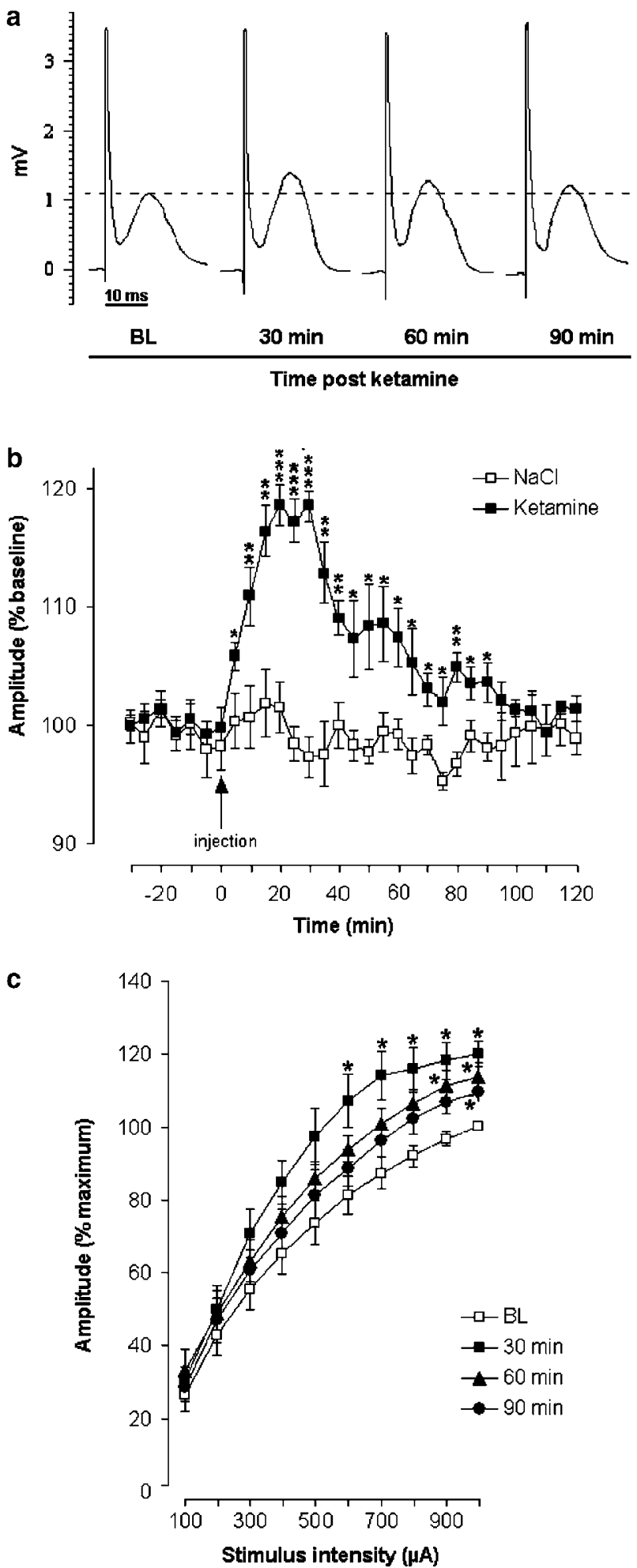

Figure 3 Effect of ketamine on PFC-NAc field potentials. (a) Examples of field potentials recorded in the NAc in response to prefrontal stimulation. (b) Time-course effect of ketamine $(n=7)$ or saline $(n=5)$ on the amplitude of the positive component. Values are expressed as percentage (mean \pm SEM) of baseline levels. ${ }^{*} p<0.05$, ${ }^{*} p<<0.01$, and **** $<0.000$ I indicate significant differences from the saline group (Student's $t$-test). (c) Input-output curves (mean \pm SEM) of the amplitude of the positive component obtained at baseline (BL) and 30, 60, and 90 min after injection of ketamine. $* 0<0.05$ indicates significant differences from the BL recording (Newman-Keuls test). 

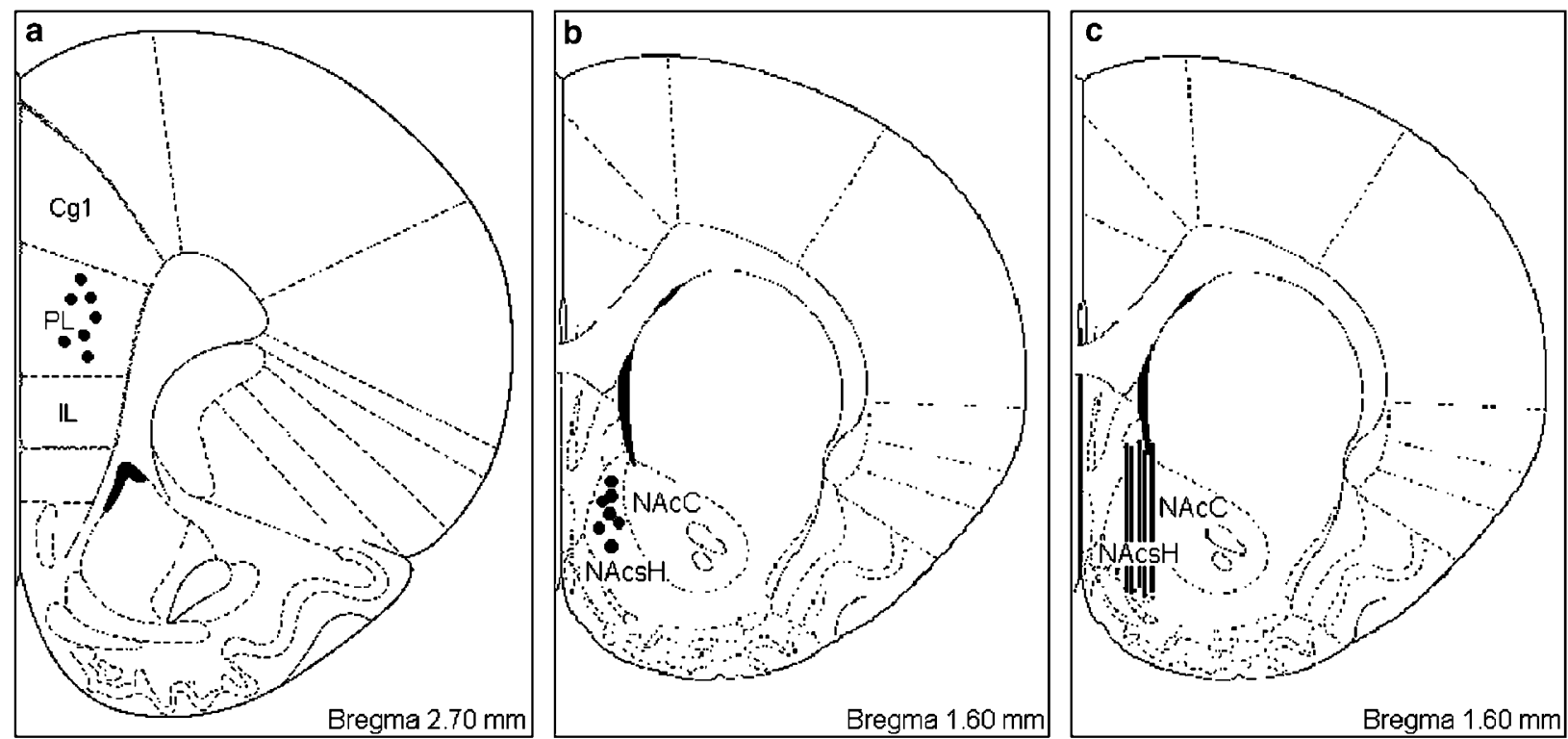

Figure 4 Histological localization of electrodes and microdialysis membranes according to the atlas of Paxinos and Watson. (a) Stimulating electrodes were placed in the prelimbic (PL) region of the PFC. (b) Recording electrodes were placed in the shell region of the NAc. (c) Microdialysis membranes were placed in the shell of the NAc. NacSh, shell of the NAc; NacC, core of the NAc.

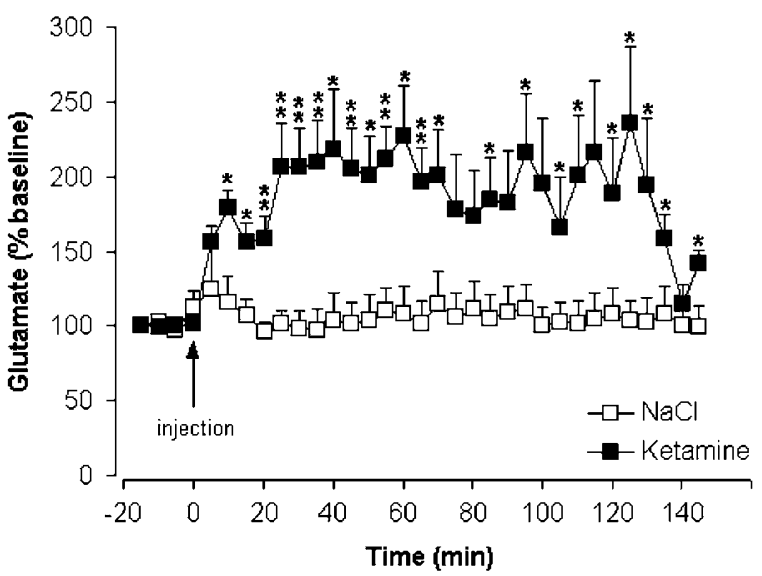

Figure 5 Time-course effect of ketamine $(n=5)$ or saline $(n=5)$ on the extracellular levels of glutamate in the NAc. Values are expressed as percentage (mean \pm SEM) of the four basal values obtained before injection. $* 0<0.05, * * * 0.01$ indicate significant differences from the saline group corresponding to the same postinjection time (Student's t-test).

$(\mathrm{F}[1,8]=10.57 ; p=0.012)$, time effect $(\mathrm{F}[32,256]=2.51$; $p<0.0001)$ and treatment $\times$ time interaction $(\mathrm{F}[32,256]=$ 2.44; $p<0.0001)$. The increase in glutamate reached maximal levels at $\sim 25 \mathrm{~min}$ after ketamine injection and remained significantly elevated above baseline levels throughout the experiment. A progressive decline of glutamate levels was however observed at 130 -min postinjection. Histological localization of probes placement is shown in Figure 4c.

\section{DISCUSSION}

We have demonstrated that ketamine, at a dose that induced disruptive effects on motor behavior and latent inhibition, produced a potentiation of synaptic transmission between the PFC and the NAc associated with an increase in the extracellular levels of glutamate in the NAc.

Acute systemic injection of a subanesthetic dose of ketamine $(25 \mathrm{mg} / \mathrm{kg})$ in rats produced an immediate motor syndrome including hyperlocomotion, stereotypies and ataxia, characteristic of NMDA antagonists. The maximal scores were observed between 10 and $15 \mathrm{~min}$ following ketamine injection and returned to baseline values after $40 \mathrm{~min}$. The time-course effect of ketamine on motor behavior in rats is similar to that previously described in mice (Irifune et al, 1995). This temporal pattern differs from those reported in rats (Druhan et al, 1996; Adams and Moghaddam, 1998) or mice (Irifune et al, 1995) with other noncompetitive NMDA antagonists, such as PCP or MK801 , which produce a longer effect with a maximal response at about 20 or 40 min postinjection, respectively.

The behavioral effects induced by the same dose of ketamine was also examined on latent inhibition in a conditioned-fear paradigm. We have found that ketamine injected before pre-exposure abolished latent inhibition. This result is consistent with two previous studies showing that ketamine or MK-801, injected before or just after preexposure, disrupted latent inhibition in a conditioned tasteaversion paradigm whereas no effect was obtained when these compounds were injected only at the conditioning stage (Aguado et al, 1994; Traverso et al, 2003). Several studies have failed however to find any disruption of latent inhibition after acute injection of noncompetitive NMDA antagonists (Moser et al, 2000) or reported abolition of latent inhibition with concomitant decrease in the conditioned response in control groups (Turgeon et al, 2000). Moreover, a recent study has shown that MK-801 induced, on the contrary, a persistent latent inhibition in a conditioned emotional response procedure when it was administered at the conditioning stage but not at the pre-exposure stage (Gaisler-Salomon and Weiner, 2003). These opposing 
effects induced by noncompetitive NMDA antagonists on latent inhibition seem therefore to depend on the time of injection and likely involve distinct mechanisms. Consistent with a drug effect depending on the time of administration, serotonergic compounds have been found to exert their effects only at the time of pre-exposure (Moser et al, 2000; Weiner, 2003). Furthermore, serotonergic projections to the NAc have been shown to influence latent inhibition (Loskutova, 2001). Recently, the NAc and its DA innervation have also been implicated in the acquisition of latent inhibition (ie the pre-exposure phase) (I Bethus, personal communication). It is possible that glutamatergic mechanisms might also participate to the acquisition of latent inhibition. Dysfunction of glutamatergic inputs to the accumbens by ketamine (Hunt et al, 2005; Kessal et al, 2005 and present results) might therefore underlie the disruption of latent inhibition observed with this compound in our conditioned-fear paradigm.

Our electrophysiological results have shown that ketamine, at the dose of $25 \mathrm{mg} / \mathrm{kg}$, induced a potentiation of PFC-evoked excitatory neurotransmission in the shell region of the NAc of freely moving rats. More specifically, the ketamine-induced increase in the amplitude of the positive component of PFC-evoked response was the most significant between 10 and $40 \mathrm{~min}$ after injection. Interestingly, this interval of time, as mentioned above, was associated with significant hyperlocomotion, stereotypies, and ataxia. Indeed, previous studies have indicated that PCP produced hyperlocomotion and stereotypies by potentiating (via a disinhibitory mechanism) glutamatergic neurotransmission at non-NMDA receptors since these behaviors could be reversed by injection of AMPA receptor antagonists or group II metabotropic glutamate receptor agonists (Moghaddam and Adams, 1998; Cartmell et al, 1999; Takahata and Moghaddam, 2003). In particular, the findings of Takahata and Moghaddam (2003) suggest that the motor effects of PCP are mediated through glutamatergic projections from the PFC to the NAc and VTA. On the basis of these data, it can be hypothesized that the potentiation of synaptic transmission we observed in the prefrontalaccumbens pathway after systemic injection of ketamine may sustain the hyperlocomotion, stereotypies, and ataxia induced by this compound, these phenomena being temporally associated.

The present microdialysis results show that systemic injection of $25 \mathrm{mg} / \mathrm{kg}$ ketamine produces a sustained and large increase in the extracellular levels of glutamate in the shell of the NAc. To date, in vivo microdialysis studies using subanesthetic doses of ketamine (ie under $50 \mathrm{mg} / \mathrm{kg}$ i.p.) have only been performed in the $\mathrm{MPFC}$ and have reported that this NMDA antagonist increased both glutamate and dopamine efflux in this structure (Moghaddam et al, 1997; Lorrain et al, 2003). Our finding is consistent with the effect of PCP, which increases glutamate efflux in the NAc (Adams and Moghaddam, 1998). The observed increase in glutamatergic transmission suggests that glutamate could be the excitatory neurotransmitter which mediates the ketamineinduced potentiation of synaptic efficacy in the NAc. Indeed, even if ketamine is expected to increase DA levels in the NAc like PCP (Adams and Moghaddam, 1998), and, although DA can facilitate hippocampal-evoked activity of accumbens neurons through D1 receptors, DA has been reported to reduce in vivo PFC-evoked response through D2 receptors (Floresco et al, 2001; Brady and O'Donnell, 2004; Goto and Grace, 2005b). Further investigations, using AMPA antagonists for example, could help to establish a direct link between the synaptic changes and the increase of glutamate levels induced by ketamine in the NAc.

Our group has previously shown in freely moving rats that ketamine, used at the same dose as in the present study, induced a depression of glutamatergic transmission between the hippocampus and the NAc (Hunt et al, 2005) and, on the contrary, a potentiation of synaptic efficacy between the basolateral amygdala and the NAc (Kessal et al, 2005). Taken together with the present electrophysiological results, these data indicate that blockade of NMDA receptors induces a profound disruption of information processing in the NAc, facilitating selectively information flow from the prefrontal cortex and amygdala. Such a disruption, as may occur in schizophrenia, could result in the transmission of inappropriate responses by accumbens output neurons and lead to abnormal behavior. In the pathophysiological model of schizophrenia proposed by Grace (2000), as mentioned above (see Introduction), a decrease in the influence of glutamatergic inputs from PFC to the NAc is hypothesized to occur based on the hypofrontality described in neuroimaging studies during working memory tasks in schizophrenic patients (Weinberger et al, 1986; Andreasen et al, 1992; Spence et al, 1998). Nevertheless, more recent neuroimaging studies using similar tasks have, on the contrary, observed an hyperfrontality (Callicott et al, 2003; Manoach, 2003). To explain these discrepancies, the authors have suggested that patients with schizophrenia would have more limited working memory capacity than healthy subjects, resulting in an inverted U-shaped curve-as a function of working memory loads-shifted to the left compared to controls. In this model, schizophrenic subjects display higher PFC activation than controls at low working memory demands and lower PFC activation at high demands. This model can therefore help to reconcile our present data, showing an enhancement of the synaptic transmission in the prefrontal-accumbens pathway, and the hypothesis of Grace. Interestingly, a recent electrophysiological study has reported that acute systemic injection of MK-801 produced a potentiation of the firing rate of prefrontal neurons, concomitant with a reduction in burst activity, and correlated with expression of stereotypies (Jackson et al, 2004). The authors have suggested that these mechanisms may contribute to impair filtering of irrelevant information and, thereby, may enhance transmission of disinformation. It can be hypothesized, on the basis of these data and the present results, that blockade of NMDA receptors may lead to transmission of irrelevant information from PFC to the NAc, which may be potentiated subsequently at the level of the NAc, leading to abnormal perseverative response.

In conclusion, the present study is the first to demonstrate that a noncompetitive NMDA antagonist ketamine, at a dose that produces schizophrenic-like effects, induces a potentiation of synaptic transmission between the PFC and the NAc in freely moving rats. This effect, which could be mediated by the increase in glutamate levels observed in the NAc following ketamine injection, may be one of 
the mechanisms by which inappropriate behavioral responses such as hyperlocomotion and stereotypies may be expressed.

\section{ACKNOWLEDGEMENTS}

This work was supported by INSERM-Avenir Program (RG).

\section{REFERENCES}

Abi-Dargham A, Gil R, Krystal J, Baldwin RM, Seibyl JP, Bowers M et al (1998). Increased striatal dopamine transmission in schizophrenia: confirmation in a second cohort. Am J Psychiatr 155: 761-767.

Adams B, Moghaddam B (1998). Corticolimbic dopamine neurotransmission is temporally dissociated from the cognitive and locomotor effects of phencyclidine. J Neurosci 18: 5545-5554.

Aguado L, San Antonio A, Perez L, del Valle R, Gomez J (1994). Effects of the NMDA receptor antagonist ketamine on flavor memory: conditioned aversion, latent inhibition, and habituation of neophobia. Behav Neural Biol 61: 271-281.

Andreasen NC, Rezai K, Alliger R, Swayze II VW, Flaum M, Kirchner $\mathrm{P}$ et al (1992). Hypofrontality in neuroleptic-naive patients and in patients with chronic schizophrenia. Assessment with xenon 133 single-photon emission computed tomography and the Tower of London. Arch Gen Psychiatr 49: 943-958.

Bert L, Robert F, Denoroy L, Stoppini L, Renaud B (1996). Enhanced temporal resolution for the microdialysis monitoring of catecholamines and excitatory amino acids using capillary electrophoresis with laser-induced fluorescence detection. Analytical developments and in vitro validations. J Chromatogr A 755: 99-111.

Bogerts B, Meertz E, Schonfeldt-Bausch R (1985). Basal ganglia and limbic system pathology in schizophrenia. A morphometric study of brain volume and shrinkage. Arch Gen Psychiatr 42: 784-791.

Brady AM, O’Donnell P (2004). Dopaminergic modulation of prefrontal cortical input to nucleus accumbens neurons in vivo. J Neurosci 24: 1040-1049.

Breier A, Su TP, Saunders R, Carson RE, Kolachana BS, de Bartolomeis A et al (1997). Schizophrenia is associated with elevated amphetamine-induced synaptic dopamine concentrations: evidence from a novel positron emission tomography method. Proc Natl Acad Sci 94: 2569-2574.

Butelman ER (1990). The effect of NMDA antagonists in the radial arm maze task with an interposed delay. Pharmacol Biochem Behav 35: 533-536.

Callicott JH, Mattay VS, Verchinski BA, Marenco S, Egan MF, Weinberger DR (2003). Complexity of prefrontal cortical dysfunction in schizophrenia: more than up or down. Am J Psychiatr 160: 2209-2215.

Carlsson A, Waters N, Carlsson ML (1999). Neurotransmitter interactions in schizophrenia-therapeutic implications. Biol Psychiatr 46: 1388-1395.

Cartmell J, Monn JA, Schoepp DD (1999). The metabotropic glutamate $2 / 3$ receptor agonists LY354740 and LY379268 selectively attenuate phencyclidine versus d-amphetamine motor behaviors in rats. J Pharmacol Exp Ther 291: 161-170.

Coyle JT, Tsai G, Goff D (2003). Converging evidence of NMDA receptor hypofunction in the pathophysiology of schizophrenia. Ann NY Acad Sci 1003: 318-327.

Csernansky JG, Joshi S, Wang L, Haller JW, Gado M, Miller JP et al (1998). Hippocampal morphometry in schizophrenia by high dimensional brain mapping. Proc Natl Acad Sci 95: 11406-11411.
Druhan JP, Rajabi H, Stewart J (1996). MK-801 increases locomotor activity without elevating extracellular dopamine levels in the nucleus accumbens. Synapse 24: 135-146.

Floresco SB, Blaha CD, Yang CR, Phillips AG (2001). Modulation of hippocampal and amygdalar-evoked activity of nucleus accumbens neurons by dopamine: cellular mechanisms of input selection. J Neurosci 21: 2851-2860.

Gaisler-Salomon I, Weiner I (2003). Systemic administration of MK-801 produces an abnormally persistent latent inhibition which is reversed by clozapine but not haloperidol. Psychopharmacology 166: 333-342.

Glantz LA, Lewis DA (2000). Decreased dendritic spine density on prefrontal cortical pyramidal neurons in schizophrenia. Arch Gen Psychiatr 57: 65-73.

Goto Y, Grace AA (2005a). Dopamine-dependent interactions between limbic and prefrontal cortical plasticity in the nucleus accumbens: disruption by cocaine sensitization. Neuron 47: 255-266.

Goto Y, Grace AA (2005b). Dopaminergic modulation of limbic and cortical drive of nucleus accumbens in goal-directed behavior. Nat Neurosci 8: 805-812.

Grace AA (1991). Phasic versus tonic dopamine release and the modulation of dopamine system responsivity: a hypothesis for the etiology of schizophrenia. Neuroscience 4: 1-24.

Grace AA (2000). Gating of information flow within the limbic system and the pathophysiology of schizophrenia. Brain Res Rev 31: 330-341.

Heckers S, Rauch SL, Goff D, Savage CR, Schacter DL, Fischman AJ et al (1998). Impaired recruitment of the hippocampus during conscious recollection in schizophrenia. Nat Neurosci 1: $318-323$.

Hunt MJ, Kessal K, Garcia R (2005). Ketamine induces dopaminedependent depression of evoked hippocampal activity in the nucleus accumbens in freely moving rats. J Neurosci 25: 524-531.

Irifune M, Shimizu T, Nomoto M, Fukuda T (1995). Involvement of $\mathrm{N}$-methyl-D-aspartate (NMDA) receptors in noncompetitive NMDA receptor antagonist-induced hyperlocomotion in mice. Pharmacol Biochem Behav 51: 291-296.

Jackson ME, Homayoun H, Moghaddam B (2004). NMDA receptor hypofunction produces concomitant firing rate potentiation and burst activity reduction in the prefrontal cortex. Proc Natl Acad Sci 101: 8467-8472.

Javitt DC, Zukin SR (1991). Recent advances in the phencyclidine model of schizophrenia. Am J Psychiatr 148: 1301-1308.

Jentsch JD, Roth RH (1999). The neuropsychopharmacology of phencyclidine: from NMDA receptor hypofunction to the dopamine hypothesis of schizophrenia. Neuropsychopharmacology 20: 201-225.

Kesner RP, Dakis M (1993). Phencyclidine disrupts acquisition and retention performance within a spatial continuous recognition memory task. Pharmacol Biochem Behav 44: 419-424.

Kessal K, Chessel A, Spennato G, Garcia R (2005). Ketamine and amphetamine both enhance synaptic transmission in the amygdala-nucleus accumbens pathway but with different time-courses. Synapse 57: 61-65.

Krystal JH, Karper LP, Seibyl JP, Freeman GK, Delaney R, Bremner JD et al (1994). Subanesthetic effects of the noncompetitive NMDA antagonist, ketamine, in humans. Psychotomimetic, perceptual, cognitive, and neuroendocrine responses. Arch Gen Psychiatr 51: 199-214.

Lahti AC, Koffel B, LaPorte D, Tamminga CA (1995). Subanesthetic doses of ketamine stimulate psychosis in schizophrenia. Neuropsychopharmacology 13: 9-19.

Laruelle M, Abi-Dargham A, van Dyck CH, Gil R, D’Souza CD, Erdos J et al (1996). Single photon emission computerized tomography imaging of amphetamine-induced dopamine release in drug-free schizophrenic subjects. Proc Natl Acad Sci 93: 9235-9240. 
Lorrain DS, Baccei CS, Bristow LJ, Anderson JJ, Varney MA (2003). Effects of ketamine and $N$-methyl-D-aspartate on glutamate and dopamine release in rat prefrontal cortex: modulation by a group II selective metabotropic glutamate receptor agonist LY379268. Neuroscience 117: 697-706.

Loskutova LV (2001). The effects of a serotoninergic substrate of the nucleus accumbens on latent inhibition. Neurosci Behav Physiol 31: 15-20.

Luby ED, Cohen BD, Rosenbaum G, Gottlieb JS, Kelley R (1959). Study of a new schizophrenomimetic drug; sernyl. Arch Neurol Psychiatr 81: 363-369.

Malhotra AK, Pinals DA, Adler CM, Elman I, Clifton A, Pickar D et al (1997). Ketamine-induced exacerbation of psychotic symptoms and cognitive impairment in neuroleptic-free schizophrenics. Neuropsychopharmacology 17: 141-150.

Malhotra AK, Pinals DA, Weingartner H, Sirocco K, Missar CD, Pickar D et al (1996). NMDA receptor function and human cognition: the effects of ketamine in healthy volunteers. Neuropsychopharmacology 14: 301-307.

Manoach DS (2003). Prefrontal cortex dysfunction during working memory performance in schizophrenia: reconciling discrepant findings. Schizophr Res 60: 285-298.

Mogenson GJ, Jones DL, Yim CY (1980). From motivation to action: functional interface between the limbic system and the motor system. Prog Neurobiol 14: 69-97.

Moghaddam B, Adams B, Verma A, Daly D (1997). Activation of glutamatergic neurotransmission by ketamine: a novel step in the pathway from NMDA receptor blockade to dopaminergic and cognitive disruptions associated with the prefrontal cortex. J Neurosci 17: 2921-2927.

Moghaddam B, Adams BW (1998). Reversal of phencyclidine effects by a group II metabotropic glutamate receptor agonist in rats. Science 281: 1349-1352.

Moser PC, Hitchcock JM, Lister S, Moran PM (2000). The pharmacology of latent inhibition as an animal model of schizophrenia. Brain Res Rev 33: 275-307.

Olney JW, Farber NB (1995). Glutamate receptor dysfunction and schizophrenia. Arch Gen Psychiatr 52: 998-1007.
Paxinos G, Watson C (1986). The Rat Brain in Stereotaxic Coordinates. Academic Press: New York.

Sams-Dodd F (1996). Phencyclidine-induced stereotyped behaviour and social isolation in rats: a possible animal model of schizophrenia. Behav Pharmacol 7: 3-23.

Sesack SR, Pickel VM (1990). In the rat medial nucleus accumbens, hippocampal and catecholaminergic terminals converge on spiny neurons and are in apposition to each other. Brain Res 527: $266-279$.

Spence SA, Hirsch SR, Brooks DJ, Grasby PM (1998). Prefrontal cortex activity in people with schizophrenia and control subjects. Evidence from positron emission tomography for remission of 'hypofrontality' with recovery from acute schizophrenia. Br J Psychiatr 172: 316-323.

Takahata R, Moghaddam B (2003). Activation of glutamate neurotransmission in the prefrontal cortex sustains the motoric and dopaminergic effects of phencyclidine. Neuropsychopharmacology 28: 1117-1124.

Traverso LM, Ruiz G, De la Casa LG (2003). Latent inhibition disruption by MK-801 in a conditioned taste-aversion paradigm. Neurobiol Learn Mem 80: 140-146.

Turgeon SM, Auerbach EA, Duncan-Smith MK, George JR, Graves WW (2000). The delayed effects of DTG and MK-801 on latent inhibition in a conditioned taste-aversion paradigm. Pharmacol Biochem Behav 66: 533-539.

Verma A, Moghaddam B (1996). NMDA receptor antagonists impair prefrontal cortex function as assessed via spatial delayed alternation performance in rats: modulation by dopamine. J Neurosci 16: 373-379.

Weinberger DR, Berman KF, Zec RF (1986). Physiologic dysfunction of dorsolateral prefrontal cortex in schizophrenia. I. Regional cerebral blood flow evidence. Arch Gen Psychiatr 43: 114-124.

Weiner I (2003). The 'two-headed' latent inhibition model of schizophrenia: modeling positive and negative symptoms and their treatment. Psychopharmacology 169: 257-297.

Zahm DS, Brog JS (1992). On the significance of subterritories in the 'accumbens' part of the rat ventral striatum. Neuroscience 50: 751-767. 